\title{
La Forestería Comunitaria en Honduras: estrategia para la reducción de la pobreza rural
}

\author{
Julio Emilio Lino Ruiz
}

Recibido: 30 de mayo de 2019. Aceptado: 14 de noviembre de 2019

\section{Introducción}

La Forestería Comunitaria (FC) en Honduras se ha considerado y explicado desde muchos puntos de vista. Algunos la han considerado enfocados desde el propio escenario de las comunidades asentadas en o alrededor de los bosques, como una necesidad para proteger los recursos naturales, de manera que sean útiles para las ciudades o comunidades urbanas. En tanto, para otros, en oposición a ese punto, la han explicado como una oportunidad generadora de beneficios que promueven el mejoramiento de las condiciones y calidad de vida de los pobladores que habitan las comunidades rurales. El dilema se presenta por su enfoque de reducción de la pobreza rural a través de promover el desarrollo de estas comunidades, al tiempo que fomenta el óptimo aprovechamiento de los recursos naturales del bosque, de lo cual también obtienen beneficios los asentamientos urbanos. Estos planteamientos que toman como punto de partida el Sistema Social Forestal y a partir de ahí justifican la $\mathrm{FC}$, no han venido funcionando como se esperaba; puesto que las organizaciones agroforestales comunitarias, usufructuarias de bosques, se enfocaron principalmente en el aprovechamiento de la madera y la resina, desatendiendo las actividades de protección del bosque.

De manera que esto nos lleva a tener frente a nosotros una pregunta mucho más profunda: ¿Es la gestión de la Forestería Comunitaria en Honduras influenciada por los centros urbanos?

\section{Desarrollo}

La FC en Honduras ha venido en evolución desde el establecimiento del Sistema Social Forestal en
1974. Se planteó desde el gobierno para generar beneficios a la población rural, incorporándola al uso 
y la protección del bosque, detener la agricultura migratoria y reducir los incendios forestales mediante la suscripción de contratos de usufructo con grupos de campesinos organizados. Se habla de ella a partir de sus orígenes históricos, como fenómeno de incidencia antrópica sobre el presente y futuro de los bosques, y como fenómeno que permite a los bosques cumplir con su función social, económica y ambiental. Generalmente estos puntos de vista no están exentos de posturas ontológicas: desde los materialistas que viniendo de los centros urbanos solo ven las maderas en los bosques, pasando por los idealistas que sostienen que los beneficios del bosques se adquieren a través de la recolección y el uso sostenible y no de la explotación de los recursos naturales de los bosques; hasta llegar a los que mantienen una postura dialéctica, quienes toman como punto de partida, el hecho de que hay que involucrar a los actores de los diversos sectores rurales y urbanos, en la toma de decisiones sobre los usos que se le debe dar a los recursos naturales de sus bosques.

Estos puntos de vista, los podemos dilucidar a través del conocimiento que nos proporciona la FC; desde donde se toma en cuenta la carestía de una sociedad cuya relación con el bosque demanda del Desarrollo Humano Integral (DHI), el Manejo Integral del Bosque (MIB) y el Manejo Integral de Fincas $(\mathrm{MIF})^{1}$; enfatizando que el fin último de la FC, es mejorar las condiciones de vida de la población de comunidades asentadas en o alrededor de los bosques, promoviendo el desarrollo rural en el marco de la construcción de procesos de organización, empresarialidad y negocios que fomenten y promuevan el establecimiento de vínculos con lo urbano; procesos que deben abordar aspectos sobre la valoración de la organización comunitaria para la gestión de mecanismos que estimulen la participación efectiva y equitativa de hombres y mujeres, como práctica de un desarrollo humano que implica que las comunidades y sus habitantes deben crear/generar destrezas y/o habilidades para analizar su realidad, identificar y priorizar problemas, identificar y evaluar posibles soluciones y propiciar las acciones más viables. Aquí se toma como base al $\mathrm{DHI}$, pues la experiencia acumulada de proyectos e investigaciones ha mostrado la importancia de las dimensiones organizativa, socioeconómica y ambiental en las decisiones de productores rurales y sus comunidades, sobre el MIB y el MIF y demás recursos forestales como fuentes de alimentación, ingreso, empleo y seguridad doméstica, que debe trascender articulaciones con lo urbano mediante diversas acciones de reciprocidad con democracia y equidad.

La principal preocupación para la gente que se encuentra asentada en o alrededor de los bosques, relacionada con la $\mathrm{FC}$; es que cuando se piensa y analiza esta actividad como una alternativa económica, se ve de muy largo plazo,

http://clifor.hn/foresteria-comunitaria/ 
a pesar que están conscientes que la misma implica asegurar la sostenibilidad de los recursos naturales sin poner en riesgo la garantía de los medios de vida para su sobrevivencia. Esta preocupación, viene a ser agravada sobre todo por la pujante conquista de territorios rurales, en donde, desde lo urbano; aparecen compradores de tierra logrando imponerse con su dinero para poner en marcha estrategias y mecanismos para controlar y apropiarse del acceso, el uso de los recursos naturales y de la mano de obra de la gente que habita estas comunidades ${ }^{2}$. Desde lo urbano se gestan procesos de aumento constante de oferta de bienes; en una propuesta eminentemente utópica de abundancia infinita, que a través del modelo productivista se impone como eje de desarrollo y empuja un crecimiento económico que plantea el aprovechamiento a corto plazo de los recursos naturales, sin pensar en las generaciones futuras.

De esta manera, en los procesos gestión de la FC, encontramos tentáculos que desde lo urbano, invaden los espacios rurales; matizando una visión sobre los bosques, que se asocia a la protección de los mismos por parte de los productores de los grupos agroforestales, pensando en asegurar su acceso al agua, la conservación de suelos, la protección de la biodiversidad y como medios de mitigación de los impactos de los desastres naturales; pero asegurando con ello los mayores beneficios para la urbe, la metrópoli y el centro (puesto que la periferia esta en lo rural). Es pues la FC, un proceso que implica la conservación del bosque por parte de las comunidades rurales, en donde se debe visibilizar la participación de las mismas en la planificación y ordenación de sus recursos naturales; incidiendo en redoblar la eficacia de las medidas de conservación y contribuyendo a que dichas comunidades se beneficien de ello; pero lo que no se dice, ni percibe, ni se acepta, es la falta de equidad en la función económica del bosque, pues la balanza se inclina a lo urbano, dejando sumidas en la pobreza a comunidades asentadas en el medio de una enorme riqueza natural.

Todo ello, incide en que los procesos de gestión de la FC en Honduras esté influenciado por lo urbano, ya que no solo se limita a ser una situación que involucre íntimamente a las comunidades $y / 0$ población rural (jóvenes y adultos de ambos sexo) en una actividad forestal. Sino que abarca una gama de aspectos que van desde pequeñas parcelas boscosas en zonas de escasez de leña a bosques con abundancia de recursos, y otros productos forestales para suplir necesidades rurales y urbanas; pasando por la producción de granos básicos (maíz y frijol) y árboles a nivel de fincas para obtener productos comercializables y la elaboración de productos forestales a nivel familiar, artesanal o de pequeña industria a fin de obtener ingresos por su venta en espacios

${ }^{2}$ Lino, J. (2019). Manual Temático sobre Desarrollo Rural. Carrera de Ingeniería Forestal. CURLA-UNAH. La Ceiba, Atlántida, Honduras. 
urbanos; hasta llegar a las actividades de manejo de los bosques que realizan los grupos agroforestales cuando usufructúan bosques públicos y/o ejidales. Todo lo cual directamente genera beneficios sociales, ambientales y económicos para el sector urbano.

\section{Conclusión}

La FC en Honduras trata de propiciar el uso responsable y sostenible del bosque, a fin de generar beneficios económicos, ambientales y sociales que contribuyan al combate de la pobreza en áreas de bosques estatales a nivel nacional; bajo un fundamento que contempla tres ejes estratégicos: el Desarrollo Humano Integral, el Manejo Integral del Bosque y el Manejo Integral de Fincas.

Aquí la actividad rural desarrollada a partir del recurso forestal, organizada colectivamente, donde las personas comparten responsabilidades y beneficios; impacta de manera directa a la población urbana, a quienes no debe vérseles únicamente como beneficiarios de los servicios ambientales, sociales y económicos ( consumidores de la producción industrial de madera, mitigación del cambio climático, secuestro de carbono, reducción de la migración del campo a la ciudad, preservación de la biodiversidad, paisajes...). La perspectiva es que en el corto o mediano plazo, la conservación de los bosques a largo plazo va a depender, entre otros factores, de un diálogo más cercano entre actores de los diferentes sectores urbanos y rurales; entre tanto ${ }^{3}$, las ciencias forestales, el conocimiento forestal tradicional y el desarrollo conjunto de procesos de FC adaptados al manejo y aprovechamiento de los bosques; deben promover y establecer una cultura organizacional e institucional con enfoques participativos entre esos diferentes sectores.

\section{Bibliografía}

Eke, J. et al. (2016). Desarrollo forestal empresarial por comunidades. FAO y CATIE. Proyecto CATIE-Finnfor II. Turrialba, Costa Rica.

GIZ, (2015). Experiencias de Forestería Comunitaria Desarrolladas por el ICF con el Apoyo de la GIZ en Honduras: Aprendiendo de la Práctica. Tegucigalpa, Honduras. 
GIZ. (2013). Forestería Comunitaria: Un Modelo de Gestión Forestal Sostenible Programa de Fomento al Manejo Sostenible de Recursos Naturales y Desarrollo Económico Local (PRORENA). Tegucigalpa, Honduras.

Janssen, M., Flores, M. (2004). Forestería Comunitaria y Desarrollo Humano Integral, un Camino al futuro. GrupoChorlavi.org. Honduras.

Lino, J. (2007). Forestería en las Comunidades Garífunas: Proyecto "Construcción de Sistemas de Aprendizaje para el Desarrollo de Honduras". Centro Internacional de Investigaciones para el Desarrollo (CIID). CURLA-UNAH. La Ceiba, Honduras.

Lino, J. (2019). Manual Temático sobre Desarrollo Rural. Carrera de Ingeniería Forestal. CURLA-UNAH. La Ceiba, Atlántida, Honduras. 